\title{
A Recovery Voltage as non-Destructive Tool for Moisture Appreciation of Oil Impregnated Pressboard: An Approach for Power Transformers Testing
}

\author{
Ferroudja Bitam-Megherbi, M'hand Mekious, and Mohammed Megherbi \\ Laboratory of Electrical Engineering Advanced Technologies (LATAGE) \\ Mouloud Mammeri University of Tizi-Ouzou, Algéria
}

\begin{abstract}
This paper is devoted to recovery voltage as a diagnostic non destructive method for an assessment of an insulating state of power transformers. The insulating pressboard used in power transformers is tested for different moisture levels. Experiments were carried out with samples from the same material intended to power transformers building. A charge and discharge of a capacitor having pressboard paper as dielectric is a suitable tool for an appreciation of the polarization and relaxation processes. The polar character of the water's molecules has an influence on the permittivity. Then the polarization of the paper will be affected by a moisture presence. Time evolution of the recovery voltage for different durations of the charges was examined. An increase of the recovery voltage with the moisture content was observed. The maximum of recovery voltage occurs much later starting from the moment of the opening of the circuit for higher moisture for all examined levels. Thus, the time separating the short circuit and the maximum's occurring can be considered like an important parameter allowing an appreciation of the moisture state of oil impregnated paper.
\end{abstract}

Index Terms: Dielectric polarization- Moisture - Nondestructive testing - Paper insulation - Power transformer insulation - Relaxation processes.

\section{Introduction}

Ageing processes as well as lifetime of power transformers are mainly dependent on the degradation state of the materials ensuring their electrical insulation. The insulating paper used in these transformers is the material which is strongly exposed to decomposition phenomena because of its affinity for the moisture. The degradation of the cellulose, the main component of the paper, is very known and amply described by scientific literature [1-3]. The damage caused to the insulating paper is generally expressed by a significant reduction of the cellulose's polymerization degree $[4,5]$. The increase of the paper's temperature due to the different losses leads to its decomposition followed by a water production, or a generation of species which lend itself to a partial polarization or ionization [1,6]. Another side of the question reveals that a bad handling of the transformer during its build or its transportation can be a source of water introduction in the oil tank [1].

The moisture can be seen as the worse contamination of an insulation using the oil impregnated paper. Therefore, the decision to continue or to stop the transformer exploitation is closely dependent on a perfect knowledge of the moisture levels [7-13]. Because of the effect of moisture on the insulation's global behavior several researchers undertook studies on the subject. These studies can be divided into two main groups, the conventional studies related to the humidity effect on the conductivity and those related to dissolved gases analysis (DGA) $[14,15]$.

New methods of diagnostic have been established as a High Performance Liquid Chromatography (HPLC) or a Dielectric Response Analysis (DRA) [16,17]. This method based on polarization and depolarization currents, generally named PDC method, has been used by several authors $[9,11,18-21]$. One of these new methods is based on a recovery voltage phenomenon occurring after voltage application followed by a short circuit. This method was

Received: June16 ${ }^{\text {th }}, 2013$. Accepted: October15 ${ }^{\text {th }}, 2013$ 
used as early as the seventies by the Budapest Technical University in Hungary [22-24]. Although the method seems to be enough old, a great interest was expressed toward it nowadays [23-26]. The method is designed by the acronym RVM (Recovery Voltage Method) and the experiments are generally carried out by mean of an apparatus named recovery voltage meter [8,23-28]. With a standard recovery voltage meter the times of exposition to the electrical field as well as the duration of the short circuit are fixed. Generally the exposition time equals twice short circuit duration. This restriction in addition to the fixed level of the acting voltage, are a further difficulties to fundamental research in a laboratory.

In this article, we focused our attention on the temporal evolution of a recovery voltage (also called return voltage) in order to establish a correlation with the rate of humidity in the insulating paper. The main aim of the work appears then as an aid for an easy determination of the humidity rate in an insulation system. This can be obtained by a good knowledge of the time corresponding to the maximum value of the recovery voltage.

The experiments were carried out with an oil impregnated paper containing different moisture levels. The samples are provided by our partner, the Electro-Industries factory, specialized in transformers building. The specimens are exposed to the electrical field during periods varying from 5 to 30 minutes. The condenser containing the paper as dielectric is discharged by a short circuit during 5 minutes. This short circuit phase is followed by a circuit opening and the examination of the voltage evolution. The recovery voltage is measured by mean of a programmable electrometer characterized by very high input impedance. The high impedance, reached by a Keithley 6514 Electrometer System, is needed to take into account the extremely great internal resistance of the experimental system.

\section{Theoretical Considerations}

The general principle of the Recovery Voltage Method is schematically given on figure 1 .

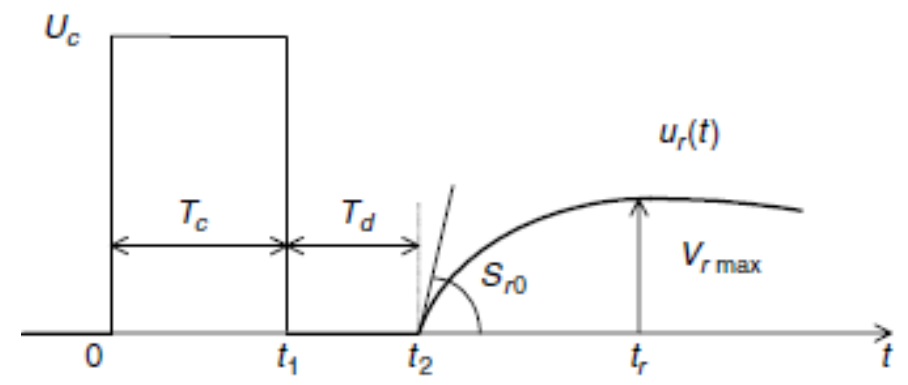

Figure 1. Schematic principle of Recovery Voltage Method.

- $\mathrm{U}_{\mathrm{c}}$ represents the dc applied voltage,

- $T_{c}$ is the time of the voltage application (time of charge).

- $T_{d}$ is the period when the system is short-circuited (time of discharge).

- $U_{r}(t)$ is the recovery voltage curve which presents a maximum value $V_{r \max }$.

Almost all the authors interested by the subject have worked on polarization spectra giving the maxima for different values of $T_{C}$ and $T_{d}=T_{C} / 2[1,8,22,25,28]$. This method was used to detect a moisture level in the paper of power transformer insulation. Let's notice that the interpretation of the RVM measurements remains still a topical question, although it is enough old [27-29]. The great advantage provided by the RVM lies in its simplicity, its non destructive character and its ability for a fast use directly on site. These considerations explain the interest expressed towards the method. Seeing the numerous works dedicated to this method, there is not doubt that its application field will be still larger in the future. However the method remains imperfect and several authors, among them Aschenbrenner et al. [27], have mentioned its shortcomings. According to them, the correct standardization of a recovery voltage meter 
will not be totally completed in the near future because of the absence of a normalization of the experimental conditions. The cause of recovery voltage being polarization and relaxation phenomena, the thermal agitation must be taken into account. However, when the experiments are carried out at ambient temperature this can be neglected, especially if the aim of the work is a comparison between samples treated in the same conditions.

For theoretical considerations, a classical modeling of the dielectric matter is represented as serial parallel combination of several entities themselves constituted by a capacitances and resistances as showed by figure $2[10,17,21]$.

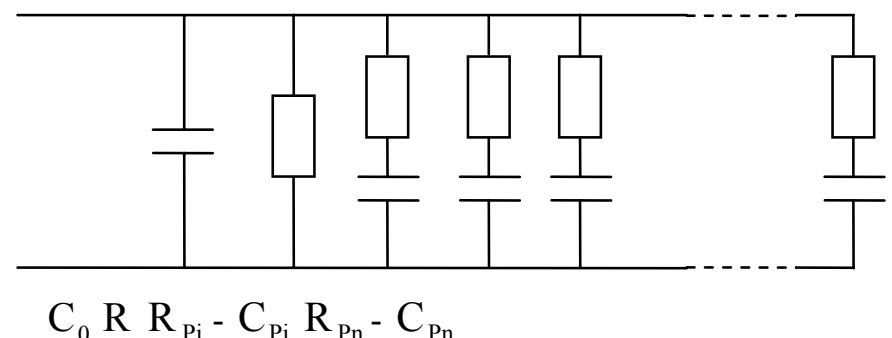

Figure 2. Schematic Representation of a real sample of dielectric matter.

On the Figure 2, $\mathrm{R}$ is the resistance of the sample, and $\mathrm{C}_{0}$ represents the geometric capacitance. The quantities $\mathrm{R}_{\mathrm{pi}}-\mathrm{C}_{\mathrm{pi}}$ are elementary components (resistances and capacitances) giving an image of the polarization processes. During the time of charge $T_{c}$ under a dc voltage, the polarization processes occur. In that case, the capacitance $\mathrm{C}_{0}$ may be totally charged in contrast to the capacitances $\mathrm{C}_{\mathrm{pi}}$ if $\mathrm{R}_{\mathrm{pi}} \cdot \mathrm{C}_{\mathrm{pi}}<\mathrm{T}_{\mathrm{c}}$, otherwise these capacitances will be partially charged only. During short circuit period, the capacitance $\mathrm{C}_{0}$ will totally lose its charge since this one corresponds to a free charge provided by the voltage source because of the presence of the object's geometric capacitance. The capacitances $\mathrm{C}_{\mathrm{pi}}$ will not be totally discharged since its time constant are greater than the short circuit duration. The capacitances $\mathrm{C}_{\mathrm{pi}}$ are related to polarization charge which is often named linked charge since it is the result of the orientation of electric dipoles. When the circuit is opened, after a short circuit period, the charged capacitances $\mathrm{C}_{\mathrm{pi}}$ will transfer a part of their charge to the capacitance $\mathrm{C}_{0}$ and an increase of potential occurs. Increasing will continue until the potential reaches a maximum. The maximum of the potential is reached when the depolarization phenomena become predominant. After the maximum is reached, one can notice a decrease depending on characteristics of the material especially its permittivity and its resistivity.

\section{Experimental Setup and Testing Procedures}

The global experimental device is showed on photograph given in figure 3. This device is similar to ones described and used by several researchers with synoptic representation given in figure 4 [8,27-29]. The tested samples are disks of pressboard paper having a $0.5 \mathrm{~mm}$ thickness and $100 \mathrm{~mm}$ diameter. They were inserted between the two stainless steel condenser's plates. The diameter of the plates is $95 \mathrm{~mm}$. The stainless steel was chosen to avoid possible chemical effects. Once the moisture is determined by weighing, the impregnation is realized following the same protocol used in the transformer's filling. After the moisture level determination, the impregnation of 48 hours is effectuated under a vacuum of 0.65 torr. During testing the samples remain immersed in order to avoid any modification of their moisture level. The pressboard samples were tested for moisture levels of $0.7 \%, 1.8 \%, 2.4 \%$ and $4.3 \%$. 


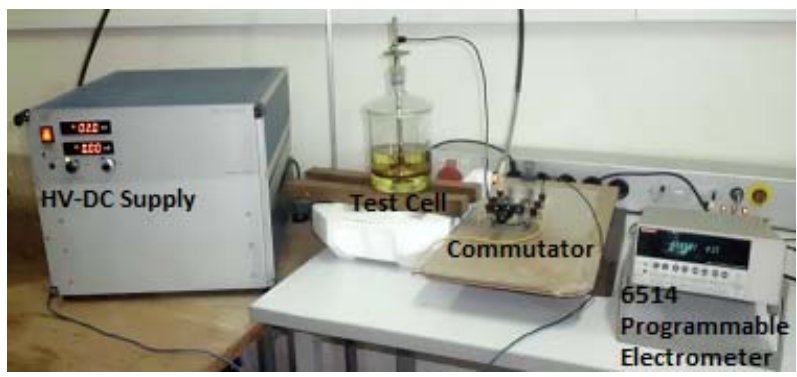

Figure 3. Global experimental setup.

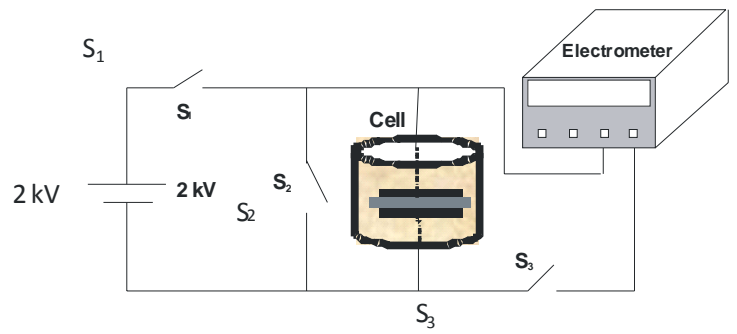

Figure 4. Schematic representation of measurement device.

The experimental procedure is achieved in accordance with the following protocol :

- During the charge time $T_{c}, S_{1}$ is switched on while $S_{2}$ and $S_{3}$ remain open, thus the sample is submitted to the electric field effect. The electric field is obtained by an application of dc voltage of $2 \mathrm{kV}$.

- During the discharge time $T_{d}, S_{1}$ is opened and $S_{2}$ closed $S_{3}$ remains in open position. The condenser is then short-circuited and should be totally discharged.

- After this discharge phase, $\mathrm{S}_{2}$ is opened and simultaneously $\mathrm{S}_{3}$ is closed. Then the recovery voltage will be measured. The recovery voltage is automatically recorded each second during a total time of 120 seconds.

\section{Experimental Results}

A. Temporal Evolution Of The Recovery Voltage, After A Short Circuit Of 5 Min, For Different Moisture Levels And Different Time Of Charge.

Figures 5 to 8 give the curves of the recovery voltage time evolution for moisture rates of $0.7 \%, 1.8 \%, 2.4 \%$ and $4.3 \%$ respectively. For each moisture level the evolution is given for different times of charge. A fine examination of curves shapes brings out several results.

a). One can notice that these curves reveal an increase of the recovery voltage with the voltage stress duration. This might be due to a polarization process characterized by a large time constant. The initial slope of the curves is greater when the time of charge is longer and we also note that the curves do not present a clearly defined maximum. 


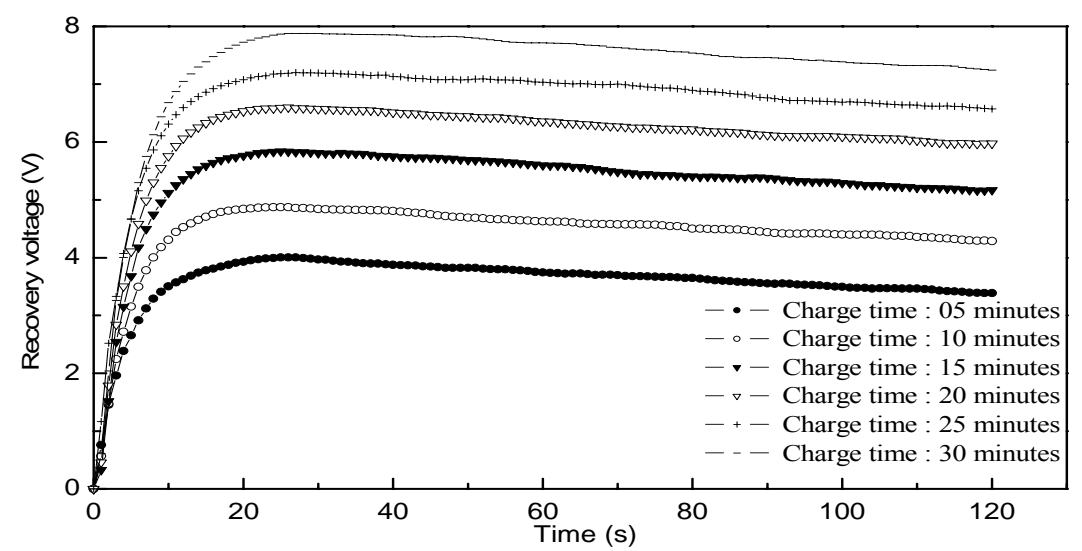

Figure 5. Recovery voltage evolution for a moisture level of $0.7 \%$ and different times of charge.

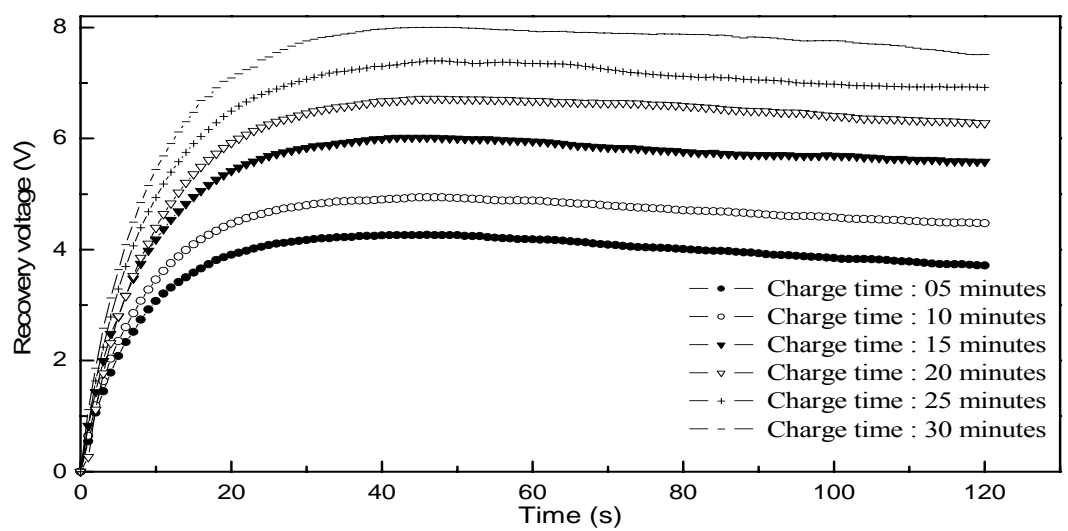

Figure 6. Recovery voltage evolution for a moisture level of $1.8 \%$ and different times of charge.

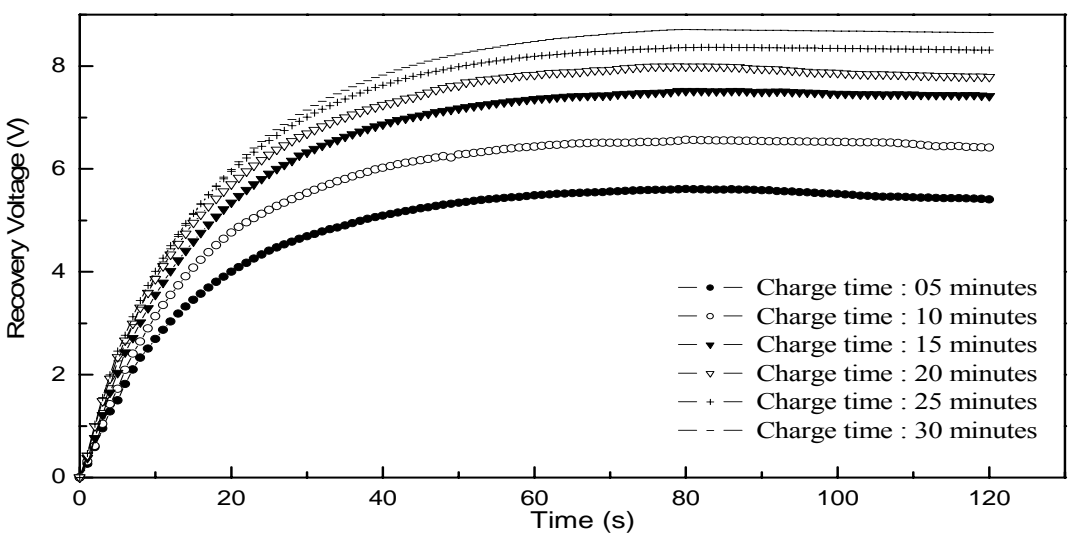

Figure 7. Recovery voltage evolution for a moisture level of $2.4 \%$ and different times of charge. 
Ferroudja Bitam-Megherbi, et al.

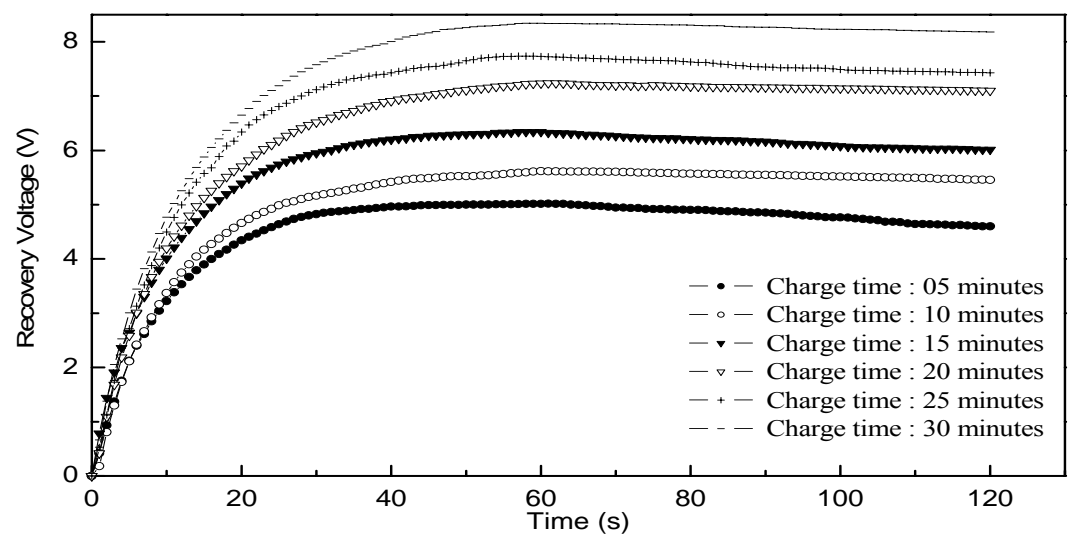

Figure 8. Recovery voltage evolution for a moisture level of $4.3 \%$ and different times of charge.

b). Concerning the recovery voltage magnitude we note, for all the charge durations, a general trend towards an increase with the moisture level. This trend is illustrated by figure 9 which give the results in the case of $30 \mathrm{~min}$ of charge and $5 \mathrm{~min}$ of discharge.

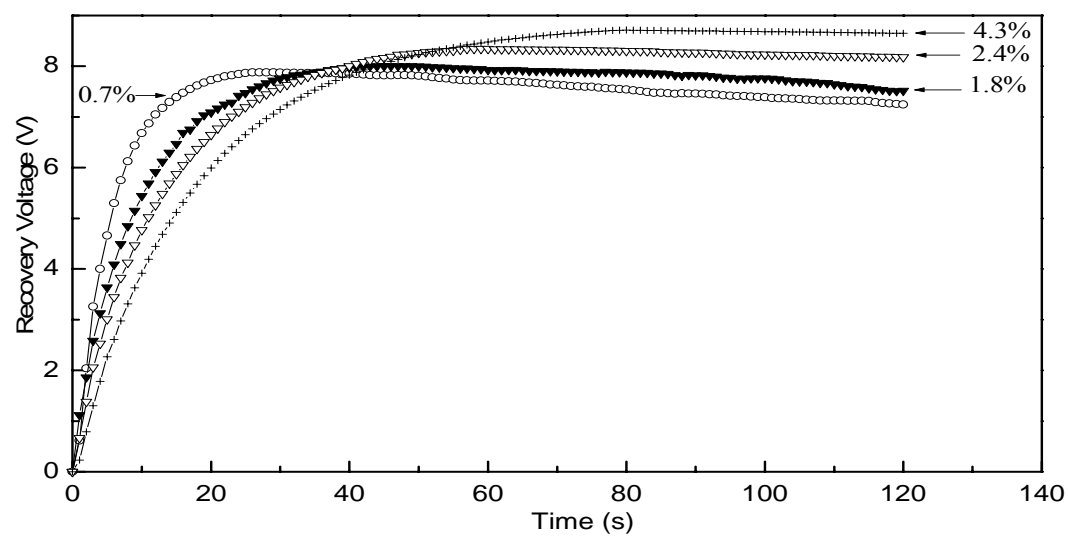

Figure 9. Recovery voltage evolution for different moisture levels.

Time of charge : $30 \mathrm{~min}$; time of discharge : $5 \mathrm{~min}$.

Another characteristic of the recovery voltage is the knowledge of $\mathrm{U}_{\mathrm{M}}$ its maximum value and $T_{M}$ the time needed to attain it. In this aim, the corresponding data were taken from the curves and reported in table 1 . These data show that the maxima practically occur after a same time, regardless of the time of voltage application. It was also noticed a displacement of these maxima towards a larger times with the moisture rate increase. For example, the maximum is reached after $26 \mathrm{~s}$ with a moisture level of $0.7 \%$ when that occurs after $80 \mathrm{~s}$ in the case of $4.3 \%$. However, it is important to note that the time corresponding to the recovery voltage maximum presents a technical importance. In fact we note that the time of the recovery voltage maximum occurs after periods varying in accordance with the moisture content. 
Table 1. Recovery voltage characteristics for different moisture levels. Applied voltage $2 \mathrm{kV}$ - Time of discharge : $5 \mathrm{~min}$

\begin{tabular}{|c|c|c|c|c|c|c|c|c|}
\hline & \multicolumn{6}{|c|}{ Time of charge (min) } \\
\hline & & & 05 & 10 & 15 & 20 & 25 & 30 \\
\hline \multirow{8}{*}{ 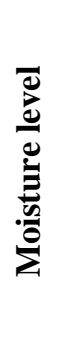 } & \multirow[b]{2}{*}{$0.7 \%$} & $\mathrm{U}_{\mathrm{M}}(\mathrm{V})$ & 4.01 & 4.87 & 5.83 & 6.59 & 7.20 & 7.88 \\
\hline & & $\mathrm{T}_{\mathrm{M}}(\mathrm{s})$ & 26 & 26 & 25 & 26 & 27 & 26 \\
\hline & \multirow[b]{2}{*}{$1.8 \%$} & $\mathrm{U}_{\mathrm{M}}(\mathrm{V})$ & 4.26 & 4.94 & 6.02 & 6.71 & 7.40 & 8.00 \\
\hline & & $\mathrm{T}_{\mathrm{M}}(\mathrm{s})$ & 46 & 46 & 46 & 46 & 46 & 46 \\
\hline & \multirow[b]{2}{*}{$2.4 \%$} & $\mathrm{U}_{\mathrm{M}}(\mathrm{V})$ & 5.02 & 5.62 & 6.34 & 7.24 & 7.73 & 8.34 \\
\hline & & $\mathrm{T}_{\mathrm{M}}(\mathrm{s})$ & 61 & 60 & 59 & 61 & 59 & 59 \\
\hline & \multirow[b]{2}{*}{$4.3 \%$} & $\mathrm{U}_{\mathrm{M}}(\mathrm{V})$ & 5.61 & 6.57 & 7.52 & 8.00 & 8.37 & 8.71 \\
\hline & & $\mathrm{T}_{\mathrm{M}}(\mathrm{s})$ & 80 & 80 & 81 & 79 & 82 & 80 \\
\hline
\end{tabular}

\section{B. Influence of The Applied Voltage on The Time Evolution of The Recovery Voltage}

On figure 10 are given the recovery voltages for lowest moisture level $0.7 \%$ and that for several voltage stresses. The chosen period for the charge was $10 \mathrm{~min}$. and the discharge time 5 $\mathrm{min}$. The results show an increase of the recovery voltage with the voltage level. Consequently the maximum values increase but they occur practically after a same period, independently of the voltage level. It was also noticed on figure 10 that the curves concentrate with the increase in the voltage level. This seems to indicate that a saturation phenomenon takes place and that the recovery voltage heads towards a limit.

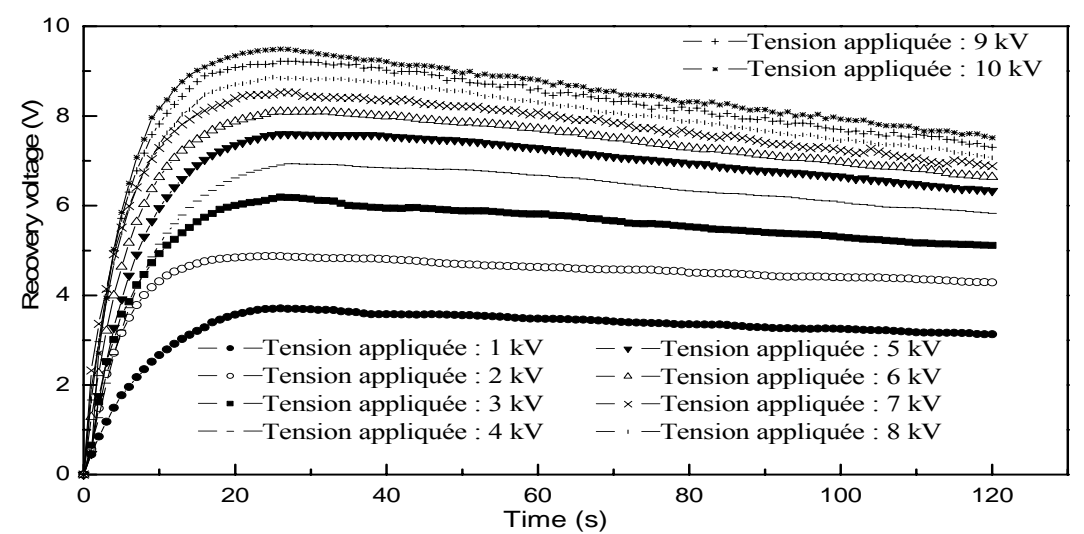

Figure 11. Influence of the applied voltage on the recovery voltage time evolution. Charge time : $10 \mathrm{~min}$; Discharge time : $5 \mathrm{~min}$

\section{Discussion and Interpretation of The Results}

\section{A. Discussion of The Experimental Results}

Experimental results presented in this article show an increase of the recovery voltage with the moisture level. This is due to the lowest resistivity caused by the high moisture as expected in accordance with our earlier work [15,30]. It appears then that the presence of water has two opposite effects. The first effect is an increase of the permittivity because of the presence of water molecules which are known for their strongly marked polar character. This will have as result an increase of the recovery voltage, in accordance with the supposition above mentioned. The second effect is a decrease of the resistivity which will lead to the recovery voltage reduction by conduction.

Another side of our results shows a growth of the recovery voltage with the level of the electrical constraint; this can be explained by the fact than the energy of the electric field depends on its intensity. However, a saturation state seems to take place. Such behavior is in conformity with equilibrium between the electric field effect and the thermal energy for a given 
voltage level. We also noticed that the recovery voltage depends on the time exposition to the electric field. That would be related to a great electrical viscosity of the material. Indeed, a great viscosity is quite possible if we consider the important dimensions of cellulose molecules.

\section{B. Phenomenological Approach}

In addition to the precedent theoretical considerations, a phenomenological description of the processes might be expressed as follows:

let's consider a condenser having between its plates a dielectric material charged under a dc voltage. It will appear, at the surfaces of its plates, an electricity quantity $Q$. Then the electric displacement $\mathrm{D}$ will have the following expression:

$$
\mathrm{D}=\varepsilon_{0}\left(\mathrm{E}_{0}+\mathrm{P}\right)
$$

$\mathrm{E}_{0}$ is the electric field corresponding to the free space, $\mathrm{P}$ is the polarization vector while $\varepsilon_{0}$ is the vacuum permittivity. Thus one can consider that the charge consists of two artificially dissociated parts $\mathrm{Q}_{\mathrm{V}}$ and $\mathrm{Q}_{\mathrm{P}} \mathrm{Q}_{\mathrm{V}}$ is the part of charge required to create the electric field corresponding to the free space $\mathrm{E}_{0}$. This field is the one we would obtain between the plates in absence of the dielectric material. $Q_{\mathrm{V}}$ is given as:

$$
\mathrm{Q}_{\mathrm{V}}=\mathrm{C}_{0} \mathrm{~V}
$$

Where $\mathrm{V}$ is the applied voltage while $\mathrm{C}_{0}$ is the geometrical capacity which only depends on condenser's form. Then the total charge is given by:

$$
\mathrm{Q}=\mathrm{Q}_{\mathrm{V}}+\mathrm{Q}_{\mathrm{P}}
$$

$\mathrm{Q}_{\mathrm{P}}$ is the charge delivered by the voltage source to compensate the polarization effects. It is well known that the insertion of any dielectric material in a condenser will induce an additional charge. When the condenser is short circuited the first part of the charge disappears quasi instantaneously since the voltage is zero. Unlike the first, the second part which compensates the induced charge will remain if the relaxation is not total. When we open the circuit the relaxation phenomenon continues but the neutralization of the charge surplus becomes impossible. Then the potential will increase due to the charge surplus, the voltage which appears is the recovery voltage that will depend on polarization relaxation phenomena. The charge surplus following the dipolar relaxation will be neutralized after a longer time by a conduction process within the material bulk. With this model it clearly appears that the material's resistivity has an important role in the temporal evolution of recovery voltage. The additional charge being due to the polarization, one also can understand the importance of the permittivity. The phenomenon of polarization and relaxation of dielectrics is often related to the electric viscosity which plays an important role in high voltage engineering. Then the evolution of the recovery voltage might be an appropriate information source on the characteristics of insulating materials used in power transformers.

\section{Conclusion}

The most significant result of this work remains certainly the established correlation between the moisture level of an insulation system and its recovery voltage. Since the paper is one of the main insulation materials used in power transformers, the present work can be a valuable tool for a test method aiming the moisture evaluation of the apparatuses. The recovery voltage method has been previously used but only to appreciate the aging, without investigations involving the effect of water which remains the main and hardest contaminant. It was clearly established that value of the recovery voltage is important and the time corresponding to recovery voltage maximum has crucial information about the moisture 
content. Indeed, the moisture content of the insulation is all the more high when time corresponding to the maximum of recovery voltage is larger.

\section{Acknowledgment}

THE AUTHORS EXPRESS THEIR THANKS TO THE ELECTRO-INDUSTRIES ENTERPRISE OF AZAZGA (TIZI-OUZOU) WHICH PROVIDED THE PRESSBOARD SAMPLES TO ACHIEVE THIS WORK.

\section{References}

[1] T. Hino, T. Suganuma, "Rapid Measurement of the Deterioration of oil immersed paper", IEEE Transactions on Electrical Insulation, Vol. EI-7, $N^{\circ} 3$, pp. 122-126, September, 1972.

[2] S. Itahashi, H. Mitsui, T. Sato, M. Sone, "Analysis of water in oil-impregnated kraft paper and its effect on conductivity", IEEE Transactions on Dielectrics and Electrical Insulation, Vol. 2, $N^{\circ}$ 6, pp. 1111-1116, December, 1995.

[3] H. Yoshida, Y. Ishioka, T. Suzuki, T. Yanari, T. Teranishi, "Degradation of insulating materials of transformers", IEEE Transactions on Electrical Insulation, Vol. EI-22, $N^{\circ} 6$, pp. 795-800, December, 1987.

[4] Y. Shang, L. Yang, Z. J. Guo, Z. Yan, "Assessing aging of large transformers by furfural investigation", $7^{\text {th }}$ IEEE International Conference on Solid Dielectrics, pp. 272-274, Eindhoven, the Netherlands, June 25-29, 2001.

[5] P. J. Baird, H. Herman, G. C. Stevens, "Non destructive measurement of the degradation of transformer insulating paper", IEEE Transactions on Dielectrics and Electrical Insulation, Vol. 13, $N^{\circ} 1$, pp. 309-318, February 2006.

[6] H. Yoshida, Y. Ishioka, T. Suzuki, T. Yanari, T. Teranishi, "Degradation of insulating materials of transformers", IEEE Transactions on Electrical Insulation, Vol. EI-22, $N^{\circ} 6$, pp. 795-800, December, 1987.

[7] B. K. Gupta, "Direct determination of moisture in solid oil-paper insulation", IEEE International Symposium on Electrical Insulation, pp. 583-586, Arlington, Virginia, USA, June 7-10, 1998.

[8] M. A. Talib, N. M. Ghazali, M. Christie, W. Zakaria, I. Hashim, S. Uthman, M. N. Jamali, "Diagnosis of transformer insulation condition using recovery voltage measurements", National Power and Energy Conference (PECon), Proceedings, pp. 329332, Bangi, Malaysia, 2003.

[9] G. Frimpong, U. Gäfvert, J. Fuhr, "Measurement and modelling of dielectric response of composite oil/paper insulation", $5^{\text {th }}$ International Conference on Properties and Applications of Dielectric Materials, pp. 86-89, Seoul, Korea, 1997.

[10] S. M. Islam, P. R. S. Jota, M. Stace, "Detection of oil-paper equilibrium moisture content in power transformers using hybrid intelligent interpretation of polarisation spectrums from recovery voltage measurements", Conference Record of the 1998 IEEE International Symposium on Electrical Insulation, Arlington, Virginia, USA, pp. 16-19, June 7-10, 1998.

[11] T. Leibfried, A. J. Kachler, "Insulation Diagnostics on Power Transformers using the Polarisation and Depolarisation Current (PDC) Analysis", IEEE International Symposium on Electrical Insulation, pp. 170-173, Boston, MA, USA, 7-10 April, 2002.

[12] M. Nikoloski, "The velocity of Drying of the already impregnated oil-paper insulation", Proceedings of the $5^{\text {th }}$ International Conference on Properties and Applications of Dielectric Materials, pp. 484-487, Seoul, Korea, May 25-30, 1997.

[13] B. Garcia, J. C. Burgos, A. M. Alonso, J. Sanz, "A moisture-in-oil model for power transformer monitoring - Part I : Theoretical foundation", IEEE Transactions on power delivery, Vol. 20, $N^{\circ} 2$, April 2005. 
[14] S. Itahashi, H. Mitsui, T. Sato, M. Sone, "Analysis of water in oil-impregnated kraft paper and its effect on conductivity", IEEE Transactions on Dielectrics and Electrical Insulation, Vol. 2, $N^{\circ}$ 6, pp. 1111-1116, December, 1995.

[15] F. Bitam-Megherbiand M. Megherbi, "The humidity influence on insulating paper DC conductivity". The XIIIth International Symposium on High Voltage Engineering (ISH 2003), Delft, The Netherlands, N706, ISBN 90-77017-79-8, August 25-29, 2003.

[16] D. Linhjell, L. Lundgaard, "Dielectric response on mineral oil impregnated cellulose and the impact of aging", IEEE Transactions on Dielectrics and Electrical Insulation, pp. 156-169, Vol. 14, N 1, February, 2007.

[17] A. Helgeson, K. T. Hogskolan, U. Gafvert, "Calculation of the Dielectric Response Function from Recovery Voltage measurements", IEEE Conference on Electrical Insulation and Dielectric Phenomena", pp. 97-101, 22-25 October, 1995.

[18] F. Bitam-Megherbi, M. Megherbi, "Time Evolution of Current through Insulating Paper under DC Voltage Stress", IEEE Transactions on Dielectrics and Electrical Insulation , Volume 14, Issue 3, pp. 656-662, June, 2007.

[19] T. K. Saha, P. Purkait, "Investigation of polarization and depolarization current measurements for the assessment of oil-paper insulation of aged transformers", IEEE Transactions on Dielectrics and Electrical Insulation, Vol. 11, pp. 144-155, 2004.

[20] V. D. Houhanessian, W. S. Zaengl, "Time domain measurements of dielectric response in oil-paper insulation systems", IEEE International Symposium on Electrical Insulation, pp. 47-52, Montreal, Canada, June, 16-19, 1996.

[21] P. Osvath, H. Zahn, "Polarisation spectrum analysis for diagnosis of oil/paper insulation system", Conference Record of the IEEE International Symposium on Electrical Insulation, Pittsburg, PA USA, pp. 155-161, June 5-8, 1994.

[22] G. Csépes, I. Hamos, R. Brooks, V. Karius, "Practical foundations of the RVM (Recovery Votage Method for Oil/Paper Insulation Diagnosis", IEEE Conference on Electrical Insulation and Dielectric Phenomena, Volume 1, pp. 345-355, 25-28 October, 1998.

[23] A. A. Paithankar, C. T. Pinto, "Transformer insulation diagnosis: recovery voltage measurement and dc absorption test", IEEE Electrical Insulation Conference and Electrical Manufacturing \& Coil Winding Conference, pp. 597-600, 16-18 October, 2001.

[24] M. Farahani, H. Borsi, E. Gockenbach, "Experience with partial discharge, dissipation factor and recovery voltage measurements for the evaluation of insulation systems of high voltage rotating machines", Annual Report Conference on Electrical Insulation and Dielectric Phenomena, pp. 454-459, 2002.

[25] A. Krivda, G. Russel, "Assessment of oil impregnated paper insulated using recovery voltage measurements", IEEE International Conference on conduction and Breakdown in Solid Dielectrics, pp. 64-68, Sweden, June 22-25, 1998.

[26] V. Aschenbrenner, T. Ucik, "Using of parameters of RVM measurement for qualitative appreciation of power transformers insulation state", Transmission and Distribution Conference and Exhibition: Asia Pacific, IEEE/PES, Vol. 3, pp. 1829-1833, 6-10 October, 2002.

[27] V. Aschenbrenner, T. Ucik, "The possibilities and limits of estimation of ageing degree of paper-oil insulation in power transformers by recovery voltage method", Dielectric Materials, Measurements and applications Conference Publication, $N^{\circ} 473$, pp. 335-340, IEE 2000.

[28] J. P. V. Bolhuis, E. Gulski, J. J. Smit, G. M. Urbani, "Interpretation of Recovery Voltage Measurements on Power Transformers", High Voltage Engineering Symposium, Conference Publication $N^{\circ} 467$, (C IEE, 22-27 August, 1999.

[29] Y. C. Kuang, G. Chen, P. Jarman, "A new model of recovery voltage of oil-paper insulation system", IEEE International Conference on Solid Dielectrics, Toulouse, France, July 5-9, 2004. 
[30] F. Bitam-Megherbi, S. Osmani and M. Megherbi, "The moisture effect on dielectric losses of insulating paper". $8^{\text {th }}$ IEEE International Conference on Solid Dielectrics, Vol. 1, pp. 443-446, Toulouse, France, July 5-9, 2004.

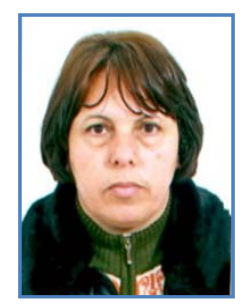

Ferroudja Bitam-Megherbi was born in 1966 in Beni Yenni, W. TiziOuzou, Algeria. She obtained her Magister degree in 1996. His doctorate thesis which was devoted to dielectric materials has been achieved in 2007. She presently teaches as senior lecturer in the Electrical Engineering Department of the MouloudMammeri University of Tizi-Ouzou. Her course is mainly oriented towards electrical characterization of dielectric materials. Her domain of interest mainly concerns the electrical insulation, especially the measurements and characterization of the insulating materials. The results of her works appear in different publications relating to dielectric materials behavior.

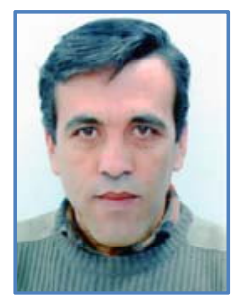

M'hand Mekious was born in 1967 in Béni Douala, W. Tizi-Ouzou, Algeria. $\mathrm{He}$ obtained her Magister degree in 2001. He prepares doctorate thesis devoted to corona discharge. He teaches in the Electrical Department of the MouloudMammeriUiversity of Tizi-Ouzou.

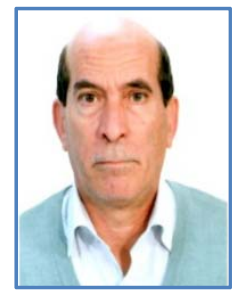

Mohammed Megherbi was born in 1951 in Mekla, W. Tizi-Ouzou, Algeria. He obtained the Doctorate of Pierre et Marie Curie University in 1989 in Paris, France. Currently he works as Professor in MouloudMammeri University of Tizi - Ouzou and is responsible for the course of electrical materials. His research field mainly concerns electrical insulation's behavior. He has several research papers in scientific meetings. He supervised several students to obtain their Masters degree in material science. 